\title{
Weight change over five-year periods and number of components of the metabolic syndrome in a Dutch cohort
}

\author{
M. Bot • A. M. W. Spijkerman · J. W. R. Twisk • \\ W. M. M. Verschuren
}

Received: 2 June 2009/Accepted: 18 December 2009/Published online: 21 January 2010

(C) The Author(s) 2010. This article is published with open access at Springerlink.com

\begin{abstract}
Overweight and obesity are associated with the metabolic syndrome (MetS). We studied the association of weight change over three consecutive 5 -year periods with the number of MetS components in people aged 20-59 years. 5735 participants from the Doetinchem Cohort Study were included. Weight was measured in round 1 and at each 5-year interval follow-up (round 2, 3 and 4). Weight change was defined as the absolute weight change between two consecutive measurements. The number of MetS components (assessed in round 2, 3 and 4) was based on the presence of the following components of the MetS: central obesity, raised blood pressure, reduced high density lipoprotein cholesterol and elevated glucose. Associations of weight change and the number of components of the MetS were analyzed with Generalized Estimating Equations for Poisson regression, stratified for 10 -year age groups. For each age group, $1 \mathrm{~kg}$ weight gain was positively associated with the number of components of the MetS, independent of sex and measurement round. The association was stronger in 30-39 years (adjusted rate ratio: 1.044; 95\%CI: 1.040 1.049) and smaller in older age groups. Compared to stable weight $(>-2.5 \mathrm{~kg}$ and $<2.5 \mathrm{~kg}$ ), weight loss $(\leq-2.5 \mathrm{~kg})$ and weight gain $(\geq 2.5 \mathrm{~kg})$ was associated with a lower and higher rate ratio respectively, for the number of
\end{abstract}

\footnotetext{
M. Bot - A. M. W. Spijkerman ( $₫)$ - W. M. M. Verschuren Centre for Prevention and Health Services Research (PZO), National Institute for Public Health and the Environment, P.O. Box 1, 3720 BA Bilthoven, The Netherlands e-mail: annemieke.spijkerman@rivm.nl

M. Bot · J. W. R. Twisk

Institute of Health Sciences, Faculty of Earth and Life Sciences, VU University Amsterdam, De Boelelaan 1085,

1081 HV Amsterdam, The Netherlands

e-mail: m.bot@uvt.nl
}

components of the MetS. Our results support the independent association of weight change with the number of MetS components with a more pronounced association in younger people.

Keywords Cardiovascular disease - Longitudinal · Metabolic syndrome . Weight change

$\begin{array}{ll}\text { Abbreviations } & \\ \text { ATP III } & \text { Adult treatment panel III } \\ \text { BMI } & \text { Body mass index } \\ \text { GEE } & \text { Generalized estimating equations } \\ \text { HDL-cholesterol } & \text { High density lipoprotein cholesterol } \\ \text { MetS } & \text { Metabolic syndrome } \\ \text { NHG } & \text { Dutch College of General Practitioners } \\ \text { TNO } & \text { Netherlands Organization of Applied } \\ & \text { Scientific Research }\end{array}$

\section{Introduction}

The prevalence of overweight (body mass index (BMI): $25-30 \mathrm{~kg} / \mathrm{m}^{2}$ ) and obesity (BMI $\geq 30 \mathrm{~kg} / \mathrm{m}^{2}$ ) is increasing rapidly [1]. In the Netherlands, the prevalence of overweight increased from one-third of the adult population in 1981 to about half of the adult population in 2004, and the prevalence of obesity doubled to $10 \%$ [2]. Obesity is strongly associated with cardiovascular diseases, diabetes mellitus [3], and the metabolic syndrome (MetS) [4-6].

The MetS predisposes an individual to cardiovascular morbidity and mortality [8] and diabetes mellitus [9]. Although several definitions of the MetS exist [10], the main components of the MetS are hypertension, hyperglycemia, central obesity, and dyslipidemia (raised triglycerides and/or reduced levels of high density lipoprotein 
cholesterol; HDL-cholesterol) [11]. The etiology of the MetS is not completely understood, and both abdominal obesity $[12,13]$ and insulin resistance $[7,14]$ have been suggested as predominant underlying risk factors.

In the 1990s, about one million (14\%) Dutch adults were reported to have the MetS [15]. In the United States, the prevalence of the MetS has increased in the nineties and is likely to rise in the future, since the MetS is related to BMI [4]. Although high weight and BMI are associated with the MetS and its components [4-6], the patterns of weight change in relation to the occurrence of the components of the MetS are less well understood. In several retrospective and prospective studies, weight gain or an increasing BMI was associated with the development of the MetS [16-20]. However, those studies were limited to young adults only [19], were performed in males only [16], or had a relatively small sample size [17]. Furthermore, some were partly based upon self-reported weight (recall) [16, 20], which tends to underestimate real weight [21].

Weight gain tends to be larger in younger individuals compared to older people [22], whereas the prevalence of the MetS increases with age [23]. Therefore, it is of importance to study the relationship between weight change and the components of the MetS in a broad age range. Hence, the aim of the present study is to describe the relationship between weight change over 5-year periods and the number of components of the MetS in a population-based longitudinal cohort study, for a priori stratified age groups. This relationship will be studied in the Doetinchem Cohort Study, a populationbased sample of 12,439 men and women aged 20-59 years at baseline, who have been followed for a period of 16 years.

\section{Methods}

Participants and study design

The study design is previously described elsewhere [24]. In brief, the Doetinchem Cohort Study is a prospective longitudinal study performed among inhabitants aged 20-59 years of Doetinchem, a town in a rural area in the Netherlands. The aim of the Doetinchem Cohort Study is to study the impact of (changes in) lifestyle factors and biological risk factors on aspects of health. Participants were randomly selected from an age- and sex-stratified sample from the civil registries of the town of Doetinchem. At baseline (1987-1991: round 1), 20155 persons were invited to visit the municipal health centre to participate in the 'Monitoring Project on Cardiovascular Disease Risk Factors'. The participation rate was $62 \%$ (12439 participants). In 1993-1998 (round 2), a random sample of 7769 persons was re-invited. Not all participants could be invited due to logistic reasons. In 1998-2002 (round 3) and 2003-2007 (round 4), those who were invited in round 2 were invited again, excluding those who emigrated, actively withdrew from the study or died. Interval between the first and second round was 6 years and interval between each follow-up was 5 years. However, we refer to 5 year intervals for all consecutive measurements for simplicity. The response rates for all follow-up measurements varied between $75 \%$ and $80 \%$, resulting in 6118, 4917 and 4521 participants for round 2, 3 and 4 , respectively. In the present analyses, we included the participants with data on at least one set of weight change over 5 years and the corresponding number of MetS components. For example, one set is the weight change between round 1 and 2 and the number of MetS components in round 2 (see Fig. 1). Those who reported to have (had) cancer $(N=401)$ were excluded from the analysis because of the potential weight loss associated with this disease. In addition, those who were pregnant during a measurement round were excluded for that specific measurement round $(N=16)$, resulting in 5735 participants to be included in the analysis. We certify that all applicable institutional and governmental regulations concerning the ethical use of human volunteers were followed during this research. The study was approved according to the guidelines of the Helsinki Declaration by the external Medical Ethics Committee of the Netherlands Organization of Applied Scientific Research (TNO).

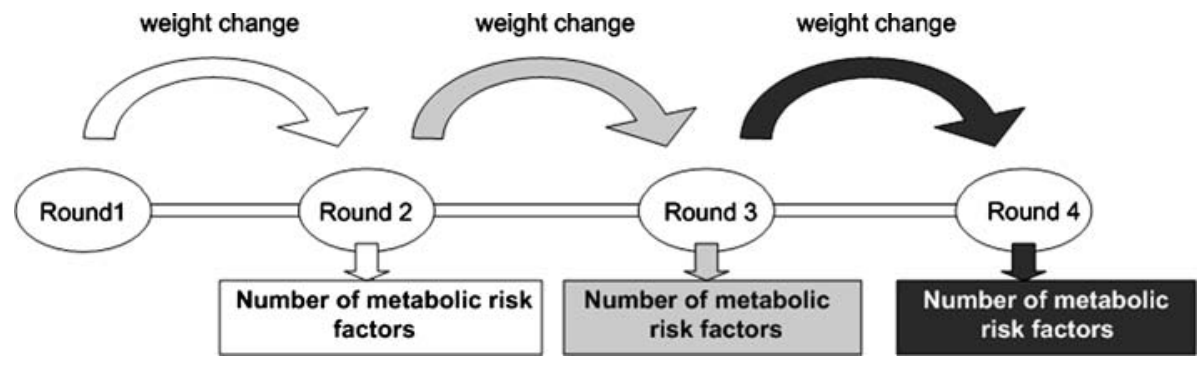

Fig. 1 Overview of analyses of 5 year weight change and number of components of the MetS. Weight change is measured between round 1 and 2 and associated with the number of components of the MetS in round 2 (white arrows and white box). Weight change between round 2 and 3 was associated with the number of components of the MetS in round 3 (gray arrows and gray box). Weight change between round 3 and 4 was associated with the number of components of the MetS in round 4 (black arrows and black box). These three sets of data were stacked and jointly analyzed with GEE 


\section{Measurements}

The study consisted of a standardized measurement of biological factors by trained personnel during a visit to the municipal health service. These measurements included anthropometric measurements, blood pressure measurements and blood sampling. Demographic characteristics, health-related information, use of medication, and lifestyle factors were examined by means of a questionnaire, which was completed at home before the physical examination.

Body weight was measured in all four rounds to the nearest $100 \mathrm{~g}$ on calibrated scales by trained staff, with participants wearing light indoor clothing with empty pockets and without shoes. To adjust for light indoor clothing, $1 \mathrm{~kg}$ was subtracted from the measured weight. Weight change was defined as the absolute change of weight in a person between two consecutive measurement rounds. Height was measured to the nearest $0.5 \mathrm{~cm}$.

Central obesity was measured by means of the waist circumference, which was measured to the nearest $0.5 \mathrm{~cm}$ at the middle of the distance between the lowest rib and the iliac crest, with participants in standing position wearing underclothing. Systolic and diastolic blood pressure were measured twice, with the participant in sitting position. Systolic pressure was recorded at the appearance of sounds (first-phase Korotkoff) and diastolic blood pressure was recorded at the disappearance of sounds (fifth-phase Korotkoff). The mean value of two measurements was used in the analysis. Non-fasting levels of HDL-cholesterol were determined at the Lipid Reference Laboratory of the Erasmus Medical Centre in Rotterdam, using standardized enzymatic methods. Non-fasting plasma glucose level was measured with the hexokinase method [25].

Educational level was assessed as the highest level of education reached during all measurements and was classified into three categories: low (intermediate secondary education or less), medium (intermediate vocational or higher secondary education) and high (higher vocational education or university). Smoking status was categorized as being a smoker, an ex-smoker or a never-smoker. Alcohol use was based on the number of glasses of alcohol per day and was categorized in none (0 glasses), light $(<1)$, moderate (1-3 for men and 1-2 for women) and heavy ( $\geq 3$ for men and $\geq 2$ for women) alcohol intake. Physical activity level was assessed with an extensive questionnaire and dichotomized in those who did and did not comply with being moderately active for at least $3.5 \mathrm{~h}$ per week.

\section{Number of MetS components}

The cut-off values of the components of the MetS were defined according to the 2005 version of the Adult Treatment Panel (ATP) III [26], with some modifications for glucose. Central obesity was defined as a waist circumference of $\geq 102 \mathrm{~cm}$ in men and $\geq 88 \mathrm{~cm}$ in women, respectively. High blood pressure was defined as a systolic blood pressure of $\geq 130 \mathrm{mmHg}$, or a diastolic blood pressure of $\geq 85 \mathrm{mmHg}$, or use of antihypertensive medication. Reduced HDL-cholesterol was defined as $<1.03 \mathrm{mmol} / \mathrm{l}$ in men and $<1.3 \mathrm{mmol} / \mathrm{l}$ in women or use of cholesterol lowering medication. Random plasma glucose measurements were used, because no fasting glucose was available. According to the recommendations of the Dutch College of General Practitioners (NHG) guidelines [27], a random glucose of $\geq 7.8 \mathrm{mmol} / \mathrm{l}$ was considered as elevated glucose. In addition, those who used medication for diabetes were also categorized as having elevated glucose.

Blood pressure and HDL-cholesterol were determined in each round. Waist circumference and glucose were measured from the second round onwards. Glucose was not determined in the first year of round 2, therefore the number of components of the MetS could not be calculated for the first year of round 2. Triglycerides were not available. The number of components of the MetS was calculated for round 2, 3 and 4, and its maximum is four.

\section{Statistical analyses}

First, baseline characteristics of the study population were described. Second, weight and the components of the MetS were described for each round and per 10-year age group (20-29 years, 30-39 years, 40-49 years and 50-59 years), based upon baseline age.

To study the relationship between 5-year changes in weight and the number of MetS components after these 5 year periods, we included all available sets of weight change and number of MetS components (see Fig. 1). To adjust for the correlation between repeated measurements in a person, we used generalized estimating equations (GEE). GEE analyses can also deal with unequal numbers of measurements and with unequally spaced observations. Based upon the correlations of the metabolic parameters over time, we chose the exchangeable correlation structure as the working correlation structure. The number of components of the MetS was analyzed using Poisson regression, which provides a rate ratio.

The relationship between weight change and the number of components of the MetS was analyzed in two ways: (1) weight change over 5 years as a continuous determinant, and (2) weight change over 5 years as a categorical determinant; i.e. three groups: stable weight (less than $2.5 \mathrm{~kg}$ weight loss and less than $2.5 \mathrm{~kg}$ weight gain $(>-2.5 \mathrm{~kg}$ and $<2.5 \mathrm{~kg}$ )), weight loss (at least $2.5 \mathrm{~kg}$ weight loss $(\leq-2.5 \mathrm{~kg})$ ), and weight gain (at least $2.5 \mathrm{~kg}$ weight gain $(\geq 2.5 \mathrm{~kg})$ ), with stable weight as the reference group. The 
$2.5 \mathrm{~kg}$ cut-off point reflects a weight gain of approximately $0.5 \mathrm{~kg}$ per year. For both analyses, the first model was adjusted for sex, round, and weight in the preceding round (Model A), and the second model was further adjusted for educational level, smoking status, alcohol use, physical activity and height (Model B). Both analyses were a priori stratified for 10-year age groups, based on age in round 1 .

Effect modification of sex, weight in the preceding round, and educational level was examined by testing the significance of the interaction term with weight change in the model. Effect modifiers are only mentioned when they were consistently found in at least three of the four age groups.

Because weight and waist circumference are correlated and waist circumference is one of the components of the MetS, the GEE analyses were repeated after removing central obesity from the components of the MetS in additional analyses.

Finally, the association of weight change with the continuous values of the individual metabolic components waist circumference, systolic and diastolic blood pressure, HDL-cholesterol, and glucose were studied with linear GEE analyses. Effect modification and confounding were studied similar to the other GEE analyses.

Statistical significance was set at $p<0.05$. All analyses were carried out in SAS 9.1 for Windows (SAS Institute Inc., Cary, NC, USA) and the GEE analyses were performed with the procedure GENMOD.

\section{Results}

Table 1 presents the baseline characteristics of the study population. A total of 2735 men (47.7\%) and 3000 women $(52.3 \%)$ were included in the analysis. For each round and 10-year age group, weight and MetS parameters are described in Table 2. The average weight increased over time. Waist circumference and blood pressure tended to worsen over the age groups and during follow-up, whereas the change in HDL-cholesterol and glucose over the age groups and over time was less clear. The number of components of the MetS increased during follow-up. For instance, the prevalence of three or more components was $10.1 \%$ in the second round compared to $17.8 \%$ in the fourth round. The most common MetS component for all age groups and measurements combined was hypertension (55\%), followed by central obesity (39\%), reduced HDLcholesterol (31\%) and elevated random glucose (5\%) (data not shown). The average number of MetS components (range $0-4$ ) in round 2 was $0.75,0.91,1.24$, and 1.61 for the age groups $20-29$ years, $30-39$ years, $40-49$ years, and 50-59 years, respectively.
Table 1 Baseline characteristics of the study sample (Data are mean (SD) or number (\%))

\begin{tabular}{ll}
\hline Characteristics & Total $(N=5735)$ \\
\hline Age (years) & $39.5(10.1)$ \\
Sex & \\
Men & $2735(47.7 \%)$ \\
Women & $3000(52.3 \%)$ \\
Educational level & \\
Low & $2779(48.5 \%)$ \\
Moderate & $1687(29.4 \%)$ \\
High & $1266(22.1 \%)$ \\
Smoking status & \\
Current smoker & $1947(34.0 \%)$ \\
Former smoker & $1649(28.8 \%)$ \\
Never smoker & $2134(37.2 \%)$ \\
Physical activity & \\
Active & $2557(54.8 \%)$ \\
Not active & $2111(45.2 \%)$ \\
\hline
\end{tabular}

${ }^{a}$ Measured at T2

In Fig. 2, the percentage individuals with weight loss $(\leq-2.5 \mathrm{~kg})$, stable weight $(>-2.5 \mathrm{~kg}$ and $<2.5 \mathrm{~kg})$ and weight gain $(\geq 2.5 \mathrm{~kg})$ over 5 years are presented per age group. The percentage of persons with weight gain became smaller with increasing age. The participants aged 20-29 years did not only have the highest percentage weight gainers $(53 \%)$, but also the highest absolute increase in weight $(6.8 \mathrm{~kg} \pm 4.0)$ in the weight gain group. Furthermore, average weight change over 5 years is larger in younger age groups (20-29 years: $3.1 \pm 5.4 \mathrm{~kg}$ ) than in older age groups (50-59 years: $1.0 \pm 4.2 \mathrm{~kg}$ ).

Table 3 (Model A) presents the regression coefficients (adjusted for sex, measurement round and weight in the preceding round) for the association of $1 \mathrm{~kg}$ weight change over 5 years with the number of components of the MetS. The a priori stratification for age groups was appropriate because significant interactions with age were found. For all age groups, $1 \mathrm{~kg}$ weight change was positively associated with the number of components, with rate ratios ranging from 1.025 (95\% CI: $1.021-1.029)$ in the 50-59 years old to 1.042 (95\% CI: $1.038-1.046)$ in the 30-39 years old. The latter rate ratio can be interpreted as follows: an increase in weight of $1 \mathrm{~kg}$ in 5 years was associated with 1.042 (95\% CI: 1.038-1.046) times more components of the MetS. Adjustment for educational level, smoking status, alcohol use, physical activity and height (Model B) did not materially change the relationship between weight change and the number of components of the MetS. Significant effect modification was present for weight change and weight in the preceding round: the association of weight change with the 
Table 2 Weight and components of the MetS per age group and total group for each round $(N=5735)($ Data are mean $(\mathrm{SD})$ or number $(\%))$

\begin{tabular}{|c|c|c|c|c|c|}
\hline & Age group $^{a}$ & Round $1(N=5735)$ & Round $2(N=5592)$ & Round $3(N=4464)$ & Round $4(N=4153)$ \\
\hline Age (years) & & $39.5(10.1)$ & $45.6(10.1)$ & $50.1(9.9)$ & $54.7(9.8)$ \\
\hline Sex (men) & & $2735(47.7 \%)$ & $2660(47.6 \%)$ & $2154(48.3 \%)$ & $1996(48.1 \%)$ \\
\hline \multirow[t]{5}{*}{ Weight (kg) } & 20-29 years & $70.1(12.5)$ & $74.0(13.7)$ & $77.1(14.0)$ & $78.9(15.2)$ \\
\hline & $30-39$ years & $72.0(12.6)$ & $75.2(13.3)$ & $77.5(13.9)$ & $78.9(14.3)$ \\
\hline & $40-49$ years & $74.1(12.5)$ & $76.6(13.2)$ & $78.5(13.6)$ & $78.6(13.8)$ \\
\hline & $50-59$ years & $75.3(11.8)$ & $76.6(12.2)$ & $77.9(12.3)$ & $77.9(13.0)$ \\
\hline & Total & $72.9(12.5)$ & $75.7(13.2)$ & $77.8(13.5)$ & $78.6(14.1)$ \\
\hline \multirow[t]{5}{*}{ Waist circumference $(\mathrm{cm})$} & 20-29 years & - & $85.4(10.8)$ & $88.8(11.0)$ & $91.2(11.9)$ \\
\hline & 30-39 years & - & $88.7(10.9)$ & $91.5(11.2)$ & $93.7(11.3)$ \\
\hline & $40-49$ years & - & $92.3(11.1)$ & $94.8(11.5)$ & $96.2(11.6)$ \\
\hline & $50-59$ years & - & $95.2(10.6)$ & $97.1(11.0)$ & $98.7(11.2)$ \\
\hline & Total & - & $90.5(11.4)$ & $93.0(11.6)$ & $94.9(11.7)$ \\
\hline \multirow[t]{5}{*}{ Systolic blood pressure (mmHG) } & 20-29 years & $118(13)$ & $118(13)$ & $119(14)$ & $125(15)$ \\
\hline & 30-39 years & $118(13)$ & $121(14)$ & $125(15)$ & $131(16)$ \\
\hline & $40-49$ years & $121(15)$ & $127(16)$ & $131(17)$ & $139(19)$ \\
\hline & $50-59$ years & $128(16)$ & $135(19)$ & $140(19)$ & $147(19)$ \\
\hline & Total & $121(15)$ & $125(17)$ & $129(18)$ & $135(19)$ \\
\hline \multirow[t]{5}{*}{ Diastolic blood pressure (mmHG) } & 20-29 years & $73(9)$ & $76(9)$ & $77(10)$ & $82(10)$ \\
\hline & 30-39 years & $75(10)$ & $79(10)$ & $81(11)$ & $85(10)$ \\
\hline & $40-49$ years & $79(10)$ & $82(11)$ & $83(11)$ & $87(10)$ \\
\hline & $50-59$ years & $81(11)$ & $83(11)$ & $83(11)$ & $86(10)$ \\
\hline & Total & $77(10)$ & $80(11)$ & $81(11)$ & $85(10)$ \\
\hline \multirow[t]{5}{*}{ HDL-cholesterol (mmol/l) } & 20-29 years & $1.26(0.29)$ & $1.37(0.36)$ & $1.34(0.35)$ & $1.39(0.36)$ \\
\hline & $30-39$ years & $1.25(0.30)$ & $1.37(0.37)$ & $1.37(0.39)$ & $1.44(0.42)$ \\
\hline & $40-49$ years & $1.26(0.33)$ & $1.40(0.41)$ & $1.39(0.41)$ & $1.45(0.43)$ \\
\hline & $50-59$ years & $1.22(0.31)$ & $1.35(0.37)$ & $1.33(0.38)$ & $1.40(0.41)$ \\
\hline & Total & $1.25(0.31)$ & $1.37(0.38)$ & $1.36(0.39)$ & $1.43(0.41)$ \\
\hline \multirow[t]{5}{*}{ Random glucose $(\mathrm{mmol} / \mathrm{l})^{\mathrm{b}}$} & 20-29 years & - & $5.0(1.0)$ & $5.1(0.9)$ & $4.9(0.9)$ \\
\hline & 30-39 years & - & $5.2(1.0)$ & $5.3(1.1)$ & $5.2(1.2)$ \\
\hline & $40-49$ years & - & $5.5(1.6)$ & $5.7(1.7)$ & $5.4(1.5)$ \\
\hline & $50-59$ years & - & $5.8(2.1)$ & $5.8(1.9)$ & $5.6(1.6)$ \\
\hline & Total & - & $5.4(1.5)$ & $5.5(1.5)$ & $5.3(1.4)$ \\
\hline \multicolumn{6}{|l|}{ Number of components of the MetS ${ }^{c}$} \\
\hline \multicolumn{2}{|l|}{0} & $2204(38.5 \%)$ & $1606(31.1 \%)$ & $1123(25.5 \%)$ & $687(16.6 \%)$ \\
\hline \multicolumn{2}{|l|}{1} & $2611(45.6 \%)$ & $1889(36.6 \%)$ & $1447(32.9 \%)$ & $1367(33.1 \%)$ \\
\hline \multicolumn{2}{|l|}{2} & $916(16.0 \%)$ & $1146(22.2 \%)$ & $1181(26.9 \%)$ & $1341(32.5 \%)$ \\
\hline \multicolumn{2}{|l|}{3} & - & $465(9.0 \%)$ & $559(12.7 \%)$ & $621(15.0 \%)$ \\
\hline \multicolumn{2}{|l|}{4} & - & $59(1.1 \%)$ & $87(2.0 \%)$ & $117(2.8 \%)$ \\
\hline
\end{tabular}

a Age group is based on age of the participant in round 1. Number of participants per age group in round 1: 20-29 years: $N=1007$; 30-39 years: $N=1873 ; 40-49$ years: $N=1689 ; 50-59$ years: $N=1166$

b The glucose measurements were based on $N=5250$ in the second round, because glucose was not determined in the first year of round 2

c The components of the MetS were: central obesity (waist circumference of $\geq 102 \mathrm{~cm}$ in men and $\geq 88 \mathrm{~cm}$ in women respectively), raised blood pressure (systolic blood pressure of $\geq 130 \mathrm{mmHg}$, or diastolic blood pressure of $\geq 85 \mathrm{mmHg}$, or use of antihypertensive medication), reduced HDL-cholesterol $(<1.03 \mathrm{mmol} / \mathrm{l}$ in men and $<1.3 \mathrm{mmol} / \mathrm{l}$ in women respectively or use of cholesterol medication), and elevated glucose level (random glucose of $\geq 7.8 \mathrm{mmol} / \mathrm{l}$ or use of medication for diabetes). The maximum number of components of the MetS in round 1 was two because waist circumference and glucose were not determined in the first round

number of components of the MetS was slightly less strong in persons with a higher weight in the preceding round.
Table 4 presents the association of weight loss and weight gain over a period of 5 years with the number of components of the MetS. For all age groups, weight loss 


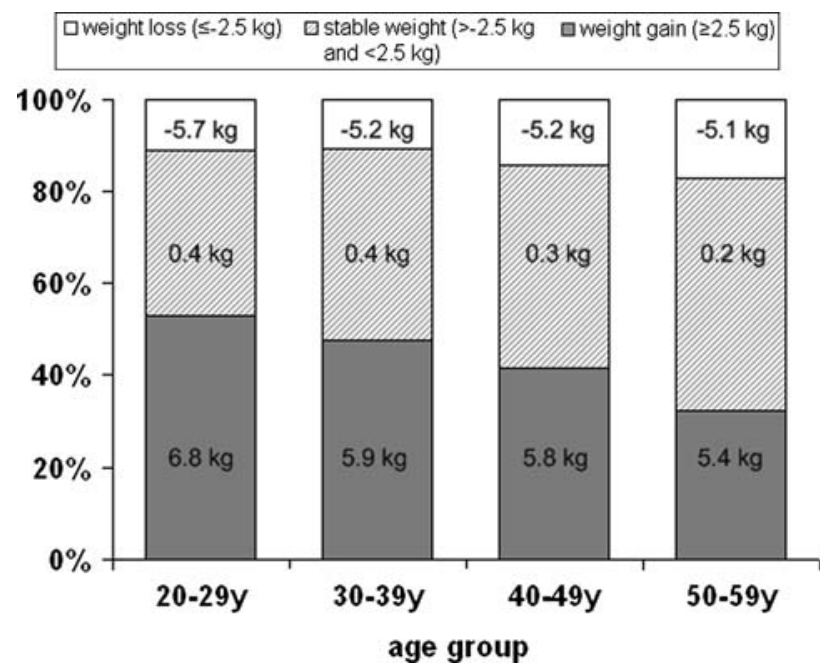

Fig. 2 Percentage individuals (height bar) and mean absolute weight change in kg over 5 years (number in the bar) averaged over the four measurement rounds per weight change category for each age group

Table 3 Association of $1 \mathrm{~kg}$ weight increase over 5 years with the number of components of the MetS per age group

\begin{tabular}{llllll}
\hline & \multicolumn{2}{l}{ Model A } & & \multicolumn{2}{l}{ Model B } \\
\cline { 2 - 3 } \cline { 5 - 6 } \cline { 5 - 6 } & Rate ratio & $95 \%$ CI & & Rate ratio & $95 \%$ CI \\
\hline 20-29 years & 1.038 & $1.031-1.045$ & & 1.038 & $1.030-1.046$ \\
30-39 years & 1.042 & $1.038-1.046$ & & 1.044 & $1.040-1.049$ \\
40-49 years & 1.031 & $1.027-1.034$ & & 1.033 & $1.029-1.037$ \\
50-59 years & 1.025 & $1.021-1.029$ & & 1.025 & $1.021-1.030$ \\
\hline
\end{tabular}

Table presents rate ratios from longitudinal Poisson regression. Model A is adjusted for: sex, measurement round and weight in the preceding round. Model B is additionally adjusted for: educational level, smoking status, alcohol use, physical activity and height

was associated with a decreased number of components and weight gain was associated with an increased number of components, compared to the stable weight group. Not surprisingly, these associations were the strongest in those aged 20-29 years because their absolute weight loss and weight gain was the largest. In persons aged 20-29 years, weight gain was associated with 1.305 (95\% CI: 1.212 1.405) times the number of components of those who remained relatively stable in weight. In persons aged $50-59$ years, $\geq 2.5 \mathrm{~kg}$ weight gain was related to only 1.141 (95\% CI: 1.101-1.182) times the number of components of those in the stable weight group. Similar differences between the age groups were found for the association of weight loss and stable weight. In the fully adjusted model (Model B), the effect of weight loss and gain remained present and became slightly more pronounced. There was significant effect modification between weight change category and weight in the preceding round for the weight gain group compared to the weight stable group, but not for the weight loss group. The strength of the association of weight gain with the number of MetS components was less in people with higher baseline weight.

\section{Additional analysis}

Weight and waist circumference are correlated and waist circumference is one of the MetS components, thus part of the dependent variable. Therefore, we repeated the analyses by excluding central obesity from the MetS components, resulting in a maximum of three MetS components. The association of $1 \mathrm{~kg}$ weight change in a 5-year period with the number of MetS components was weaker in the analysis without central obesity than in the analysis including central obesity as part of the MetS components, but still statistically significant for all age groups (rate ratios ranging from 1.015 to 1.033 ), indicating that the association of weight change with the number of MetS components does not depend solely on its association with waist circumference. A similar pattern of weaker but significant associations was observed for the weight gain/ weight loss analyses.

Finally, we studied the associations of $1 \mathrm{~kg}$ weight change over 5 years with the individual metabolic components with longitudinal linear regression analysis. One

Table 4 Association of weight loss and gain over 5 years with the number of components of the MetS per age group

\begin{tabular}{|c|c|c|c|c|c|c|c|c|}
\hline & \multicolumn{4}{|c|}{ Weight loss $(\leq-2.5 \mathrm{~kg})$} & \multicolumn{4}{|c|}{ Weight gain $(\geq 2.5 \mathrm{~kg})$} \\
\hline & \multicolumn{2}{|l|}{ Model A } & \multicolumn{2}{|l|}{ Model B } & \multicolumn{2}{|l|}{ Model A } & \multicolumn{2}{|l|}{ Model B } \\
\hline & Rate ratio & $95 \% \mathrm{CI}$ & Rate ratio & $95 \% \mathrm{CI}$ & Rate ratio & $95 \% \mathrm{CI}$ & Rate ratio & $95 \%$ CI \\
\hline 20-29 years & 0.773 & $0.685-0.872$ & 0.768 & $0.680-0.867$ & 1.305 & $1.212-1.405$ & 1.318 & $1.224-1.418$ \\
\hline 30-39 years & 0.790 & $0.738-0.845$ & 0.783 & $0.729-0.840$ & 1.282 & $1.234-1.333$ & 1.310 & $1.258-1.363$ \\
\hline $40-49$ years & 0.809 & $0.768-0.853$ & 0.800 & $0.758-0.844$ & 1.208 & $1.169-1.249$ & 1.224 & $1.183-1.267$ \\
\hline $50-59$ years & 0.888 & $0.843-0.934$ & 0.873 & $0.828-0.920$ & 1.141 & $1.101-1.182$ & 1.132 & $1.091-1.175$ \\
\hline
\end{tabular}

Table presents rate ratios from Poisson regression. Reference group is the stable weight group $(>-2.5 \mathrm{~kg}$ and $<2.5 \mathrm{~kg})$. Model A is adjusted for: sex, measurement round and weight in the preceding round. Model B is additionally adjusted for: educational level, smoking status, alcohol use, physical activity and height 
$\mathrm{kg}$ weight change was related to an increase in waist circumference $(\beta: 0.838 \mathrm{~cm} ; 95 \%$ CI: 0.821-0.856), systolic blood pressure ( $\beta$ : $0.432 \mathrm{mmHg} ; 95 \%$ CI: $0.379-0.486$ ), diastolic blood pressure $(\beta: 0.355 \mathrm{mmHg} ; 95 \%$ CI: $0.318-$ $0.392)$ and glucose ( $\beta: 0.014 \mathrm{mmol} ; 95 \%$ CI: $0.009-0.020)$ and a decrease in HDL-cholesterol $(\beta$ : $-0.011 \mathrm{mmol} ; 95 \%$ CI: -0.012 to -0.011 ) in the fully adjusted model (model B). No consistent effect modification was observed for the individual metabolic components.

\section{Discussion}

In this prospective cohort study, weight change over a 5 -year period was associated with increased number of components of the MetS, independent from sex, measurement round and other cardiovascular risk factors. Compared to those who remained relatively stable in weight, weight gain $(\geq 2.5 \mathrm{~kg})$ was related to an increase in the number of components of the MetS, whereas weight loss $(\leq-2.5 \mathrm{~kg})$ was related to a decrease in the number of components. The association of weight change and the number of MetS components was stronger in younger than in older people. Furthermore, there was negative effect modification with weight in the preceding round, indicating that the association of weight change and the number of MetS components in those already high in weight was slightly weaker.

As weight gain is an important public health concern, more insight into the effect of weight change on metabolic components is needed. Because weight change and the development of MetS components varies with age [22, 23], we studied the effect of weight change on the number of MetS components for different age groups. In the present study, in all adult age groups, weight gain predisposed an individual to increased number of MetS components, compared to those who maintained a stable weight. Similar associations were observed by Hillier et al. [18], who showed in French individuals aged 30-64 years that larger weight gain was associated with higher rates of both developing and maintaining the MetS than smaller weight gain. In addition, in the CARDIA study, a prospective study in persons aged 18-30 years at baseline, a stable BMI over time was associated with a smaller incidence of the MetS compared to a rise in BMI over time, regardless of the baseline BMI [19]. Furthermore, in the longitudinal study of Ferreira et al. [17], it was found that persons with the MetS at age 36 had a more marked increase of BMI from the age of 21 onwards.

In our study, weight gain was positively related with the individual MetS components waist circumference, systolic and diastolic blood pressure, and glucose level and negatively with HDL-cholesterol. This is in accordance with the findings of several other longitudinal studies in adults with different duration of follow-up (range: 2-11 years) [18, 28-31]. Weight gain was related to unfavorable changes in waist circumference [18], blood pressure, hypertension [18, 28-31], and lipid profile [18, 30, 31]. For glucose level, Norman et al. [31] found a positive association between weight change and fasting glucose level. Czernichow et al. [29] did not observe this association, possibly due to the short follow-up time of 2 years in this study. Similar to our results, Hillier et al. [18] found that weight change was most strongly related to waist circumference out of all individual metabolic components.

It is well known that components of the MetS tend to worsen with age [19] and that the prevalence of the MetS increases with age $[32,33]$. Our study is in line with these findings, because the number of components of the MetS increased with age. In our analyses with weight change as a continuous variable, those aged 30-39 years showed the largest rate ratio for the association of weight change and number of MetS components. Since absolute weight gain was larger in younger adults, it might be important to prevent weight gain in younger adults. In the weight loss/ weight gain analyses, the higher rate ratio observed in young adults is probably largely the result of the higher absolute weight change in young adults.

In our study we found that those who lost weight had a reduction in the number of components compared to the participants who had a stable weight. The favorable effect of weight loss on the metabolic risk profile has also been shown in weight loss intervention studies in obese adults [34]. However, weight loss and weight loss maintenance are hard to achieve [35]. Recent studies demonstrated an association of repeated weight loss [36] and weight fluctuation [20] with the MetS. Therefore, weight stabilization may be a more important public health goal [19]. Weight gain prevention in adults can be accomplished by preventing a positive energy balance by stimulating physical activity and reducing energy intake, and by focusing on the environment to make the healthy choice the easiest choice [37].

Because no standard definition of weight loss, stable weight and weight gain exists [38], we set the cut-off value of weight change on $2.5 \mathrm{~kg}$. Sensitivity analyses with cutoff values of 1 and $4 \mathrm{~kg}$ confirmed our findings that the association of weight change with the number of components of the MetS was stronger in younger age groups (data not shown).

What distinguishes the present study from earlier ones is that the relationship between weight change and the MetS is quantified in a broad age group (20-59 years) with a follow-up of 16 years. Another strength is that weight change was not self-reported, but measured by trained personnel. Further strengths are its large sample size, the 
prospective design, and the availability of up to four measurements per individual. The response rate of the follow-up measurements was also relatively high ( $\geq 75 \%$ from the second round onwards). Finally, by using GEE analysis all data are effectively used.

One of the limitations is selective loss to follow-up. Compared to the participants included in this study, those who were lost to follow-up were more often lower educated, current smokers and of younger age. In addition, baseline BMI and baseline blood pressure were higher in those who were lost to follow-up, whereas baseline HDLcholesterol was lower. No difference was found for sex, weight and alcohol consumption at baseline (data not shown). Our study population is therefore not representative for the Dutch population, and the results might not be generalizable to young, low educated persons with a relative adverse cardiovascular risk profile. Another important limitation is the lack of information about triglycerides. Therefore, it was not possible to determine the relationship between weight change and the MetS. Instead, our study included four metabolic components, derived from the 2005 version of the ATP III definition of the MetS [26] and looked at the number of MetS components. In addition, glucose level was measured non-fasting. This might be less accurate since food intake affects the level of blood glucose [39]. We compensated for this by using a higher cut-off value reflecting fasting glucose levels, as reported in Rutten et al. [27].

While it seems that certain components of the MetS are prone to cluster, the exact components and cut-off values of the MetS differ over the existing definitions [12]. Furthermore, the number of MetS components in round 2 is somewhat larger in older age groups than in younger people. The different rate ratio's observed for the age groups might also reflect a ceiling effect. However, as the number of metabolic syndrome components at baseline in the oldest age group is not extremely high, we feel that the ceiling effect does not completely account for the observed difference in rate ratio's between age groups.

With the dichotomization of the components information is lost. Analyses with the continuous values of the individual components showed associations in the expected direction for each separate component and strengthened our findings.

In sum, weight gain is positively associated with the number of components of the MetS, whereas weight loss is negatively associated with this number. Our study shows that the effect of weight change on the number of MetS components is different for various age groups. Prevention of weight gain might be relevant in younger adults in particular, for whom the association of weight change with the number of MetS components is the strongest and the weight gain is the largest.
Acknowledgments The Doetinchem Cohort Study was financially supported by the Ministry of Health, Welfare and Sport of the Netherlands. The authors would like to thank the field workers of the Municipal Health Services in Doetinchem (C. te Boekhorst, I. Hengeveld, L. de Klerk, I. Thus, and ir. C. de Rover) for their contribution to the data collection of this study. The project director is dr. ir. W.M.M. Verschuren. Logistic management is provided by P. Vissink and the secretarial support was provided by E.P. van der Wolf. The data management is provided by ir. A. Blokstra, drs. A.W.D. van Kessel and ir. P.E. Steinberger. The data of the first measurement round of the Doetinchem cohort study are collected within the framework of the Monitoring Project on Cardiovascular Disease Risk Factors (1987-1991), of which the project director was prof. dr. D. Kromhout. The data of the second research round were collected within the framework of the Monitoring Project on Risk Factors for Chronic Diseases (MORGEN study, 1993-1997), of which the project directorship consisted of prof.dr. J.C. Seidell, dr. H.A. Smit, dr. H.B. Bueno de Mesquita en dr. ir. W.M.M. Verschuren. Logistic support was provided by A. Jansen, ir. J. Steenbrink-van Woerden and P. Vissink.

Open Access This article is distributed under the terms of the Creative Commons Attribution Noncommercial License which permits any noncommercial use, distribution, and reproduction in any medium, provided the original author(s) and source are credited.

\section{References}

1. Friedman N, Fanning EL. Overweight and obesity: an overview of prevalence, clinical impact, and economic impact. Dis Manag. 2004; 7(Suppl 1):S1-6.

2. Schokker DF, Visscher TL, Nooyens AC, van Baak MA, Seidell JC. Prevalence of overweight and obesity in the Netherlands. Obes Rev. 2007;8(2):101-8.

3. Visscher TL, Seidell JC. The public health impact of obesity. Annu Rev Public Health. 2001;22:355-75.

4. Ford ES, Giles WH, Mokdad AH. Increasing prevalence of the metabolic syndrome among US Adults. Diabetes Care. 2004; 27(10):2444-9.

5. Carnethon MR, Loria CM, Hill JO, Sidney S, Savage PJ, Liu K. Risk factors for the metabolic syndrome: the Coronary Artery Risk Development in Young Adults (CARDIA) study, 19852001. Diabetes Care. 2004;27(11):2707-15.

6. Park YW, Zhu S, Palaniappan L, Heshka S, Carnethon MR, Heymsfield SB. The metabolic syndrome: prevalence and associated risk factor findings in the US population from the Third National Health and Nutrition Examination Survey, 1988-1994. Arch Intern Med. 2003;163(4):427-36.

7. Reaven GM. Banting lecture 1988. Role of insulin resistance in human disease. Diabetes. 1988;37(12):1595-607.

8. Gami AS, Witt BJ, Howard DE, Erwin PJ, Gami LA, Somers VK, et al. Metabolic syndrome and risk of incident cardiovascular events and death: a systematic review and meta-analysis of longitudinal studies. J Am Coll Cardiol. 2007;49(4):403-14.

9. Lorenzo C, Okoloise M, Williams K, Stern MP, Haffner SM. The metabolic syndrome as predictor of type 2 diabetes: the San Antonio heart study. Diabetes Care. 2003;26(11):3153-9.

10. Day C. Metabolic syndrome, or What you will: definitions and epidemiology. Diab Vasc Dis Res. 2007;4(1):32-8.

11. Third Report of the National Cholesterol Education Program (NCEP). Expert Panel on Detection, Evaluation, and Treatment of High Blood Cholesterol in Adults (Adult Treatment Panel III) final report. Circulation 2002;106(25):3143-21. 
12. Carr DB, Utzschneider KM, Hull RL, Kodama K, Retzlaff BM, Brunzell JD, et al. Intra-abdominal fat is a major determinant of the National Cholesterol Education Program Adult Treatment Panel III criteria for the metabolic syndrome. Diabetes. 2004; 53(8):2087-94.

13. Cameron AJ, Boyko EJ, Sicree RA, Zimmet PZ, Söderberg S, Alberti KG, et al. Central obesity as a precursor to the metabolic syndrome in the AusDiab study and Mauritius. Obesity (Silver Spring). 2008;16(12):2707-16.

14. Ferrannini E, Haffner SM, Mitchell BD, Stern MP. Hyperinsulinaemia: the key feature of a cardiovascular and metabolic syndrome. Diabetologia. 1991;34(6):416-22.

15. Bos MB, de Vries JH, Wolffenbuttel BH, Verhagen H, Hillege JL, Feskens EJ. The prevalence of the metabolic syndrome in the Netherlands: increased risk of cardiovascular diseases and diabetes mellitus type 2 in one quarter of persons under 60 . Ned Tijdschr Geneeskd. 2007;151(43):2382-8.

16. Everson SA, Goldberg DE, Helmrich SP, Lakka TA, Lynch JW, Kaplan GA, et al. Weight gain and the risk of developing insulin resistance syndrome. Diabetes Care. 1998;21(10):1637-43.

17. Ferreira I, Twisk JW, van Mechelen W, Kemper HC, Stehouwer CD. Development of fatness, fitness, and lifestyle from adolescence to the age of 36 years: determinants of the metabolic syndrome in young adults: the Amsterdam growth and health longitudinal study. Arch Intern Med. 2005;165(1):42-8.

18. Hillier TA, Fagot-Campagna A, Eschwege E, Vol S, Cailleau M, Balkau B. Weight change and changes in the metabolic syndrome as the French population moves towards overweight: the DESIR cohort. Int J Epidemiol. 2006;35(1):190-6.

19. Lloyd-Jones DM, Liu K, Colangelo LA, Yan LL, Klein L, Loria $\mathrm{CM}$, et al. Consistently stable or decreased body mass index in young adulthood and longitudinal changes in metabolic syndrome components: the Coronary Artery Risk Development in Young Adults Study. Circulation. 2007;115(8):1004-11.

20. Vergnaud AC, Bertrais S, Oppert JM, Maillard-Teyssier L, Galan $\mathrm{P}$, Hercberg S, et al. Weight fluctuations and risk for metabolic syndrome in an adult cohort. Int J Obes. 2008;32(2):315-21.

21. Gorber SC, Tremblay M, Moher D, Gorber B. A comparison of direct vs self-report measures for assessing height, weight and body mass index: a systematic review. Obes Rev. 2007;8(4):307-26.

22. Nooyens ACJ, Visscher TLS, Verschuren WMM, Schuit AJ, Boshuizen HC, van Mechelen W, et al. Age, period and cohort effects on body weight and body mass index in adults: The Doetinchem Cohort Study. Public Health Nutr. 2008;24:1-9.

23. Hildrum B, Mykletun A, Hole T, Midthjell K, Dahl AA. Agespecific prevalence of the metabolic syndrome defined by the International Diabetes Federation and the National Cholesterol Education Program: the Norwegian HUNT 2 study. BMC Public Health. 2007;7(147):220.

24. Verschuren W, Blokstra A, Picavet H, Smit H. Cohort profile: The Doetinchem cohort study. Int J Epidemiol. 2008;37(6):1236-41.

25. Tietz NW, editor. Clinical guide to laboratory tests. 3rd ed. Philadelphia: Pa WB Saunders Company; 1995. p. 268-73.
26. Grundy SM, Cleeman JI, Daniels SR, Donato KA, Eckel RH, Franklin BA, et al. Diagnosis and management of the metabolic syndrome: an American Heart Association/National Heart, Lung, and Blood Institute Scientific Statement. Circulation. 2005; 112(17):2735-52.

27. Rutten GEHM, De Grauw WIC, Nijpels G, Goudswaard AN, Uitewaal PJM, Van der Does FEE, et al. NHG-Standaard Diabetes mellitus type 2 [Dutch College of General Practitioners Guideline Diabetes mellitus type 2]. Huisarts Wet. 2006;49(3): 137-52.

28. Droyvold WB, Midthjell K, Nilsen TI, Holmen J. Change in body mass index and its impact on blood pressure: a prospective population study. Int J Obes (Lond). 2005;29(6):650-5.

29. Czernichow S, Mennen L, Bertrais S, Preziosi P, Hercberg S, Oppert JM. Relationships between changes in weight and changes in cardiovascular risk factors in middle-aged French subjects: effect of dieting. Int J Obes Relat Metab Disord. 2002;26(8): 1138-43.

30. Rainwater DL, Mitchell BD, Comuzzie AG, VandeBerg JL, Stern MP, MacCluer JW. Association among 5-year changes in weight, physical activity, and cardiovascular disease risk factors in Mexican Americans. Am J Epidemiol. 2000;152(10):974-82.

31. Norman JE, Bild D, Lewis CE, Liu K, West DS. The impact of weight change on cardiovascular disease risk factors in young black and white adults: the CARDIA study. Int J Obes Relat Metab Disord. 2003;27(3):369-76.

32. Kraja AT, Borecki IB, North K, Tang W, Myers RH, Hopkins $\mathrm{PN}$, et al. Longitudinal and age trends of metabolic syndrome and its risk factors: the Family Heart Study. Nutr Metab. 2006;3:41.

33. Kuzuya M, Ando F, Iguchi A, Shimokata H. Age-specific change of prevalence of metabolic syndrome: longitudinal observation of large Japanese cohort. Atherosclerosis. 2007;191(2):305-12.

34. Case CC, Jones PH, Nelson K, O'Brian Smith E, Ballantyne CM. Impact of weight loss on the metabolic syndrome. Diabetes Obes Metab. 2002;4(6):407-14.

35. Elfhag K, Rossner S. Who succeeds in maintaining weight loss? A conceptual review of factors associated with weight loss maintenance and weight regain. Obes Rev. 2005;6(1):67-85.

36. Holme I, Sogaard AJ, Haheim LL, Larsen PG, Tonstad S. Repeated Weight Loss is Associated with the Metabolic Syndrome and Diabetes: Results of a 28 Year Re-screening of Men in the Oslo Study. Metab Syndr Relat Disord. 2007;5(2):127-35.

37. Hill JO. Understanding and addressing the epidemic of obesity: an energy balance perspective. Endocr Rev. 2006;27(7):750-61.

38. Truesdale KP, Stevens J, Lewis CE, Schreiner PJ, Loria CM, Cai $\mathrm{J}$. Changes in risk factors for cardiovascular disease by baseline weight status in young adults who maintain or gain weight over 15 years: the CARDIA study. Int J Obes (Lond). 2006;30(9): 1397-407.

39. American Diabetes Association. Postprandial blood glucose. Diabetes Care. 2001;24(4):775-8. 